\section{Editorial}

REV EXP MED 2019;5(4).

\title{
Ética e investigación: un camino en equipo
}

\author{
Ethics and research: a team path
}

\section{Antero Enrique Yacarini-Martínez 1.a}

La ética es una disciplina filosófica orientada al estudio de actos buenos o malos, es decir la conducta racional del hombre (Ethos), enfocada hacia la racionalización de la "Experiencia Moral" como un conjunto de valores y virtudes mínimos que una sociedad acepta para garantizar la convivencia pacífica y el respeto mutuo. Este sustento de la ética ha permitido darle cuerpo a la ética médica y luego a la bioética. En ese sentido el investigador Dr. Van Rensselaer Potter, propuso en su libro: Bioethics: a Bridge to the future: a la Bioética, como una nueva disciplina que une dos mundos, que en su opinión hasta ese momento habían transitado por caminos distintos: el mundo de los hechos, de la ciencia, y el mundo de los valores, y en particular la ética ${ }^{(1,2)}$.

Por otro lado, según la "Enciclopedia de Bioética" (1978), define a la bioética como: "el Estudio sistemático de la conducta humana en el ámbito de las Ciencias de la vida y de la salud examinada a la luz de los valores y de los principios morales" (3).

Considerando una visión más integral, según Elena Postigo, "la bioética es el estudio sistemático e interdisciplinar de las acciones del hombre sobre la vida humana, vegetal y animal, considerando sus implicaciones antropológicas y éticas, con la finalidad de ver racionalmente aquello que es bueno para el hombre, las futuras generaciones y el ecosistema, para encontrar una posible solución clínica o elaborar una normativa jurídica adecuada".

El proceso de investigación se sostiene en la aplicación y uso de los principios de la bioética: beneficencia, justicia, no maleficencia y autonomía, los cuales buscan la verdad científica mediante valores morales objetivos, dentro de un contexto ético que sea respetuoso de la persona humana, sus derechos inalienables y su dignidad intrínseca. Así este proceso se evidencia a través del actuar de un Comité de Ética en Investigación y el uso correcto del consentimiento informado en investigaciones que lo ameritan.

En definitiva, los principios bioéticos, las normas, nacionales e internacionales en ética de investigación, se orientan directamente a proteger a los seres vivos que son usados como unidades de experimentación; sin embargo, al protegerlos, indirectamente también protegen al investigador y a la propia institución donde se realiza el estudio.

Por tanto, la ética de la investigación científica no se limita a la protección del sujeto que se estudia; su ejercicio e influencia se extienden a la reflexión en torno al impacto que todo el proceso investigativo tiene en diversos actores del desarrollo científico, incluyendo investigadores, patrocinadores, academia o universidad y sociedad. No se trata, entonces, de un ejercicio limitado a la protección de los derechos de sujetos vulnerables, se trata de una disciplina que en el marco de la bioética, busca mantener una mirada atenta al impacto de la ciencia sobre el futuro de la humanidad. De esta forma, las declaraciones, las normas y los propios fundamentos de la investigación científica deben ser vistos dentro de un marco más amplio que los tradicionales principios a los que nos expuso la temprana historia de la bioética ${ }^{(4,5)}$.

En conclusión, la conjugación del binomio ética e investigación aporta al fortalecimiento del desarrollo e innovación y la integridad científica, partiendo del reconocimiento y valoración de vida humana, vegetal y animal, teniendo en cuenta sus implicaciones antropológicas y éticas.

\footnotetext{
1. Escuela de Medicina Humana, Universidad Católica Santo Toribio de Mogrovejo, Chiclayo, Perú.

a. Biólogo, Microbiólogo. Maestro en Ciencias con mención en Microbiología.
} 


\section{REFERENCIAS BIBLIOGRAFICAS}

1. Ávila Morales JC, Robayo Téllez AV. La Bioética y su Inseparable Relación con la Investigación. REDIIS [Internet]. 7 de diciembre de 2017 [citado 5 de enero de 2020]; 10. Disponible en: http://revistas.sena.edu.co/index.php/ rediis/article/view/1231

2. Ugalde A, Homedes N. Los comités de ética de investigación en América Latina: ¿Para qué sirven? RCB [Internet]. 27may2019 [citado 6ene.2020]; 14(1). Disponible en: https://revistas.unbosque.edu.co/index.php/RCB/article/view/2540

3. Suárez Obando F. Un marco ético amplio para la investigación científica en seres humanos: más allá de los códigos y las declaraciones. La propuesta de Ezekiel J. Emanuel pers bioét. 2015; 19(2): 182-197.

4. Perales A. Reflexiones Sobre Ética de Investigación en Seres Humanos. Rev Peru Med Exp Salud Pública. 2010; 27(3): 438-42.

5. UNESCO. Declaración Universal de Bioética y Derechos Humanos. [Internet]. Disponible en: http://portal.unesco.org/es/ev.php-URL_ ID=31058\&URL_DO=DO_TOPIC\&URL_SECTION=201.html 